\title{
Critical Review of Prasugrel for Formulary Decision Makers
}

\author{
Jeremy A. Schafer, PharmD; Nicole K. Kjesbo, PharmD, BCPS; \\ and Patrick P. Gleason, PharmD, BCPS, FCCP
}

\begin{abstract}
BACKGROUND: Cardiovascular disease, including acute coronary syndromes (ACS) comprising ST-elevation and non-ST-elevation myocardial infarction (STEMI/NSTEMI) and unstable angina (UA), remains the leading cause of death in the United States. The direct and indirect costs of cardiovascular disease are estimated to surpass $\$ 165$ billion in 2009 . Antiplatelet pharmacotherapy has been shown to reduce ACS-related death and is part of the American College of Chest Physicians (ACCP) and the American College of Cardiology /American Heart Association (ACC/AHA) treatment guideline recommendations.
\end{abstract}

OBJECTIVE: To provide formulary decision makers with information on the pharmacokinetics and pharmacodynamics of the thienopyridine antiplatelet agent prasugrel as well as an analysis of available efficacy and safety data and its risk-benefit profile in comparison with clopidogrel.

METHODS: Literature search for information on prasugrel with a focus on (a) the Trial to Assess Improvement in Therapeutic Outcomes by Optimizing Platelet Inhibition with Prasugrel-Thrombolysis in Myocardial Infarction (TRITON-TIMI) 38 trial, (b) briefing documents from the FDA available as of March 1, 2009, and (c) ongoing phase III studies of prasugrel.

RESULTS: TRITON-TIMI 38 was a double blind, randomized superiority study involving 13,608 patients with moderate- to high-risk acute coronary syndromes with scheduled percutaneous coronary intervention (PCI). TRITON-TIMI 38 data were available in a published manuscript and in an FDA review. Study patients were randomized to either prasugrel or clopidogrel once daily. The primary end point (composite of death from cardiovascular causes, nonfatal myocardial infarction, or nonfatal stroke) occurred in 643 patients $(9.9 \%)$ in the prasugrel group and 781 patients $(12.1 \%)$ in the clopidogrel group $(\mathrm{HR}=0.82,95 \% \mathrm{Cl}=0.73-0.93, P=0.002)$. Non-coronary artery bypass graft (non-CABG) TIMI major hemorrhage occurred in 146 patients $(2.4 \%)$ in the prasugrel group compared with 111 patients $(1.8 \%)$ in the clopidogrel group $(\mathrm{HR}=1.32,95 \% \mathrm{Cl}=1.03-1.68$, $P=0.03$ ). A subanalysis of the TRITON-TIMI 38 trial data revealed a net harm for patients with a prior history of stroke or transient ischemic attack (TIA) when treated with prasugrel $(\mathrm{HR}=1.54,95 \% \mathrm{Cl}=1.02-2.32, P=0.04)$. Combination prasugrel and aspirin is currently being studied in comparison with clopidogrel and aspirin for the treatment of UA/NSTEMI patients that are medically managed.

CONCLUSIONS: For every 1,000 patients treated with prasugrel instead of clopidogrel, a total of 24 end points would be prevented at the cost of 10 additional bleeding events. On February 3, 2009, the FDA Cardiovascular and Renal Drugs Advisory Committee deemed this to be an acceptable riskbenefit profile. The committee recommended a label contraindication for patients with prior history of transient ischemic attack or stroke. Treatment versus time analyses demonstrated both early and sustained benefit for prasugrel compared with clopidogrel. However, prasugrel was associated with fewer cardiovascular events prevented per bleeding case the longer the duration of therapy. The study population of TRITON-TIMI 38 was limited to patients undergoing PCI. Managed care decision makers should consider specific criteria limiting prasugrel use to health plan members with characteristics similar to the study population in TRITON-TIMI 38 that benefited from treatment and avoiding use in patients with prior history of stroke or TIA. More data are needed before prasugrel can be recommended in patient groups not addressed by TRITON-TIMI 38 .

J Manag Care Pharm. 2009;15(4):335-43

Copyright $\odot 2009$, Academy of Managed Care Pharmacy. All rights reserved.

\section{What is already known about this subject}

- Cardiovascular disease is the leading cause of death in the United States. The estimated direct and indirect cost of cardiovascular disease is $\$ 165.4$ billion in 2009 .

- American College of Chest Physicians (ACCP) and the American College of Cardiology/American Heart Association (ACC/AHA) treatment guidelines recommend the use of antiplatelet medications (aspirin, clopidogrel) for patients presenting with unstable angina (UA), non-ST-elevation myocardial infarction (NSTEMI) and ST-elevation myocardial infarction (STEMI). Aspirin (75 mg-325 mg) is recommended indefinitely, and clopidogrel (300 $\mathrm{mg}$ loading dose and $75 \mathrm{mg}$ once daily maintenance) is recommended for use up to 12 months. A $600 \mathrm{mg}$ loading dose of clopidogrel is recommended in select populations (i.e., NSTEMI patients undergoing percutaneous coronary intervention [PCI]).

- Prasugrel is a thienopyridine being studied for the treatment of acute coronary syndromes (ACS)

\section{What this review adds}

- Prasugrel demonstrated significantly enhanced reductions in the composite end point of cardiovascular death, nonfatal myocardial infarction, and nonfatal stroke compared with clopidogrel in the TRITON-TIMI 38 trial. Prasugrel was also associated with a significantly higher risk of bleeding, including fatal bleeding compared with clopidogrel.

- For each 1,000 patients treated with prasugrel instead of clopidogrel, a total of 24 cardiovascular end points would be prevented at the expense of 10 bleeding events. The FDA Cardiovascular and Renal Drugs Advisory Committee considered this to be a favorable risk benefit profile and unanimously voted (9-0) for approval of prasugrel

- Patients with a prior history of stroke or transient ischemic attack (TIA) had worse outcomes on prasugrel compared with the rest of the study group. The FDA Cardiovascular and Renal Drugs Advisory Committee recommended that prasugrel be contraindicated in patients with history of stroke or TIA

- The benefit of prasugrel post-PCI may vary with time. For patients with STEMI, the difference in primary cardiovascular end points prevented between prasugrel and clopidogrel was greatest at 18 days. The difference was sustained but did not increase through 450 days in STEMI patients. Patients with NSTEMI experienced sustained increases in benefit through 450 days. Fewer cardiovascular end points may be prevented per bleeding event with extended therapy.

- Prasugrel has been studied in a limited ACS population undergoing PCI. Managed care decision makers should consider limiting use of prasugrel to patients who are representative of the TRITON-TIMI 38 population that showed benefit until more data are available in other patient groups. Patients likely to benefit include those younger than 75 with no history of stroke and undergoing PCI (not coronary artery bypass graft [CABG]). 
A cute coronary syndromes (ACS) comprise non-ST elevation myocardial infarction (NSTEMI), unstable angina (UA), and ST-elevation myocardial infarction (STEMI). ${ }^{1}$ Percutaneous coronary intervention (PCI), a therapeutic procedure to treat stenotic coronary arteries, is recommended for both STEMI and UA/NSTEMI by the American College of Cardiology/ American Heart Association (ACC/AHA) and the American College of Chest Physicians (ACCP). ${ }^{2-6}$

Cardiovascular disease (CVD) is the leading cause of death in the United States with 1 of every 2.8 deaths attributed to CVD. ${ }^{1,7,8}$ In 2006, ACS was the discharge diagnosis for more than 1.3 million hospitalizations. Of these, 810,000 were diagnosed with myocardial infarction (MI) and 537,000 were diagnosed with UA. ${ }^{1}$ Additionally, an estimated 1,313,000 inpatient PCI procedures, 448,000 inpatient bypass procedures, 1,115,000 inpatient diagnostic cardiac catheterizations, 114,000 inpatient implantable defibrillators, and 418,000 pacemaker procedures were performed for inpatients in the United States during $2006 .{ }^{9}$ The estimated direct and indirect cost of CVD for 2009 is $\$ 165.4$ billion. ${ }^{1}$

According to the ACC/AHA, PCI is recommended for most patients presenting with UA/NSTEMI. ${ }^{2}$ A more conservative approach such as medical therapy may be recommended for UA/ NSTEMI patients with a low-risk score or based upon patient or physician preference in absence of high-risk features..$^{10}$ Patients that present with STEMI are also candidates for PCI. ${ }^{10}$ Data from the CRUSADE (Can Rapid Risk Stratification of Unstable Angina Patients Suppress Adverse Outcomes With Early Implementation of the ACC/AHA Guidelines) Quality Improvement Initiative (March 2000-September 2002) revealed that only 26.4\% of highrisk NSTEMI ACS patients underwent PCI within 48 hours following presentation. ${ }^{11}$ Current ACCP and ACC/AHA treatment guidelines recommend the use of antiplatelet medications for patients presenting with UA, NSTEMI, and STEMI. In addition to indefinite aspirin ( $75 \mathrm{mg}-325 \mathrm{mg}$ daily) therapy, clopidogrel (300 mg loading followed by $75 \mathrm{mg}$ daily maintenance) is recommended for up to 12 months for the majority of patients for the secondary prevention of ischemic events following an ACS. ${ }^{3-6} \mathrm{~A}$ $600 \mathrm{mg}$ loading dose of clopidogrel is recommended in certain populations (i.e., NSTEMI patients undergoing PCI; Table 1). ${ }^{3}$

Like clopidogrel, prasugrel is a thienopyridine adenosine diphosphate (ADP) receptor antagonist that irreversibly inhibits platelet activation and aggregation. ${ }^{10}$ Prasugrel is approximately 10 -fold more potent than clopidogrel and 100-fold more potent than ticlopidine in inhibiting platelet aggregation, inhibiting thrombus formation, and prolonging bleeding times..$^{10}$ The active metabolites of prasugrel and clopidogrel appear to have antiplatelet effects that are approximately equipotent in vitro. ${ }^{10}$ Clinical studies have provided significant information regarding the pharmacokinetics, pharmacodynamics, safety, and efficacy of prasugrel. The objective of this article is to provide a critical review of these aspects and provide managed care decision makers with insights regarding the risks and benefits of prasugrel.

\section{Pharmacokinetics and Pharmacology}

The bioavailability of prasugrel exceeds $79 \% .^{10}$ The peak plasma concentration of the active metabolite occurs 30 minutes after dosing. ${ }^{10,12}$ The parent compound is not detectable in the plasma. Protein binding is estimated to be $98 \%$ with an apparent volume of distribution ranging from $30 \mathrm{~L}$ to $84 \mathrm{~L} .{ }^{10}$ Prasugrel is cleared via the liver and kidney with an estimated clearance between 73 L per hour and $266 \mathrm{~L}$ per hour. ${ }^{10}$ Approximately $68 \%$ of the dose is excreted in the urine and $27 \%$ in the feces as inactive metabolites. ${ }^{10,12}$ The half life of the active metabolite of prasugrel is 7.4 hours (range 2-15 hours) compared with 8 hours for the active metabolite of clopidogrel. ${ }^{10,13}$ Repeated dosing of prasugrel $10 \mathrm{mg}$ daily did not result in accumulation. ${ }^{10}$

Following oral administration, prasugrel is metabolized by esterases in the blood and intestines to an inactive thiolactone. ${ }^{14}$ Cytochrome P (CYP) enzymes, principally $3 \mathrm{~A} 4$ and 2B6, convert the thiolactone to the active metabolite R-138727..$^{10,14-16}$ The parent molecule is not active in vitro. ${ }^{13}$ Similarly, clopidogrel is converted from the inactive parent compound to the active metabolite via the CYP system in a 2-step process compared with one for prasugrel. $.^{14} \mathrm{R}-138727$, like the active metabolite of clopidogrel, binds irreversibly to the P2Y12 ADP receptor site, causing inhibition of platelet aggregation for the life of the platelet. . $^{1416}$

The PRINCIPLE-TIMI 44 trial randomized patients undergoing planned PCI to treatment with prasugrel or clopidogrel within 1 hour of PCI. The treatment regimens were prasugrel $60 \mathrm{mg}$ loading dose and $10 \mathrm{mg}$ daily maintenance dose $(\mathrm{n}=102)$ or clopidogrel $600 \mathrm{mg}$ loading dose and $150 \mathrm{mg}$ daily maintenance dose ( $\mathrm{n}=99)$ for 14 days. ${ }^{17}$ Clopidogrel $600 \mathrm{mg}$ has demonstrated more rapid platelet inhibition, faster onset, and fewer nonresponders compared with the standard $300 \mathrm{mg}$ dose. ${ }^{17}$ PRINCIPLE-44 was not powered to be a clinical end point study. The primary end point was the difference in inhibition of platelet aggregation (IPA) between prasugrel and clopidogrel at 6 hours and 14 days. ${ }^{17}$ IPA at 6 hours is clinically relevant as ACC/AHA guidelines recommend that clopidogrel be administered at least 6 hours prior to planned catheterization or PCI. ${ }^{2}$ The IPA at 6 hours was significantly greater with prasugrel $60 \mathrm{mg}(74.8 \pm 13.0 \%)$ compared with clopidogrel $600 \mathrm{mg}(31.8 \pm 21.1 \%)(P<0.001){ }^{17}$ This difference was apparent at 30 minutes $(30.8 \pm 29.0 \%$ prasugrel vs. $4.9 \pm 13.2 \%$; $P<0.001) .{ }^{17}$ At day $14 \pm 2$, the IPA was significantly greater with prasugrel $10 \mathrm{mg}(61.3 \pm 17.8 \%)$ compared with clopidogrel $150 \mathrm{mg}(46.1+21.3 \%)(P<0.001){ }^{17}$

\section{Drug Interactions}

A retrospective cohort study $(n=8,205)$ found concomitant use of clopidogrel and proton-pump inhibitor (PPI) after hospital discharge for ACS was associated with a significant increased risk of adverse outcomes, including increased risk of death or rehospitalization for ACS, higher risk of hospitalizations for recurrent ACS, and more revascularization procedures than use of clopidogrel without PPI. ${ }^{18}$ An open-label, 4-period crossover 
Critical Review of Prasugrel for Formulary Decision Makers

\section{TABLE 1 Clopidogrel and Aspirin Dosing per AHA/ACC Guidelines for ACS}

Patient Group

Patients presenting with NSTEMI ACS without aspirin allergy

Patients presenting with NSTEMI ACS with aspirin allergy

For NSTEMI ACS patients who are at moderate or greater risk management strategy

For NSTEMI ACS patients who are at moderate or greater risk for an ischemic event and for whom an early conservative or delayed invasive strategy of management is to be used For NSTEMI ACS patients who undergo PCI for an ischemic event and who will undergo an early invasive

Dose and Regimen

Immediate aspirin 162 to $325 \mathrm{mg}$ orally and then daily oral aspirin 75 to $100 \mathrm{mg}$

Clopidogrel $300 \mathrm{mg}$ oral bolus, followed by $75 \mathrm{mg}$ daily indefinitely

"Upstream" treatment either with clopidogrel (300 mg oral bolus, followed by $75 \mathrm{mg}$ per day) or a small-molecule IV GP IIb/IIIa inhibitor (eptifibatide or tirofiban)

Upstream treatment with clopidogrel (300 mg oral bolus, followed by $75 \mathrm{mg}$ daily)

Loading dose of $600 \mathrm{mg}^{\mathrm{a}}$ of clopidogrel given at least 2 hours prior to planned PCI

followed by $75 \mathrm{mg}$ daily

If patients cannot tolerate aspirin, loading dose of clopidogrel $600 \mathrm{mga}$ be given at least 24 hours prior to planned PCI
Acute STEMI with or without fibrinolytic therapy

Acute STEMI

Aspirin 160-325 mg orally at initial evaluation, then 75 to $162 \mathrm{mg}$ daily indefinitely

Dosing if patients receive fibrinolytic agents or no reperfusion therapy:

75 years or younger: $300 \mathrm{mg}$

Older than 75 years: $75 \mathrm{mg}$

Followed by: $75 \mathrm{mg}$ daily for 28 days

Acute STEMI with no coronary stent

Clopidogrel $75 \mathrm{mg}$ daily up to 1 year

Acute STEMI undergoing primary PCI followed by $75 \mathrm{mg}$ daily

Source: Goodman SG, et al. Chest. 2008;133(6 Suppl):708S-775,)5 and Harrington RA, et al. Chest. 2008;133(6 Suppl):670S-707S.6

aThe $600 \mathrm{mg}$ loading dose of clopidogrel more rapidly inhibits platelet aggregation, but the additive clinical efficacy and the safety of higher oral loading doses have not been rigorously established.

ACS = acute coronary syndromes; AHA/ACC=American Heart Association/American College of Cardiology; GP = glycoprotein; NSTEMI=non-ST-elevation myocardial infarction; $P C I=$ percutaneous coronary intervention; STEMI=ST-elevation myocardial infarction.

study ( $\mathrm{n}=26)$ found lansoprazole decreased prasugrel's active metabolite $\mathrm{AUC}_{0 \text {-tlast }}$ and $\mathrm{C}_{\max }$ by $13 \%$ and $29 \%$, respectively, but did not affect IPA. In the same study, lansoprazole tended to lower IPA after a clopidogrel dose. ${ }^{19}$ An analysis performed by the U.S. Food and Drug Administration (FDA) did not suggest a significant difference between prasugrel with or without PPIs or histamine-2 receptor antagonists. ${ }^{10}$ More study is needed regarding the concomitant use of prasugrel and PPIs. An open-label trial found no effect on the pharmacokinetics or pharmacodynamics of the active metabolites of prasugrel or clopidogrel when administered with histamine-2 antagonists. ${ }^{20}$

The major CYP isoenzymes that metabolize prasugrel to the active metabolite are CYP3A4 and CYP2B6. ${ }^{10}$ The FDA review notes that there were no clinically important drug-drug interactions for prasugrel with a CYP3A4 inhibitor (ketoconazole), a CYP3A4 inducer (rifampin), or a CYP2B6 substrate (bupropion). ${ }^{10}$ An open-label, randomized, crossover, 2-arm, parallel-group study found that atorvastatin $80 \mathrm{mg}$ per day for 7 days did not produce a significant change in exposure to prasugrel's active metabolite after a $60 \mathrm{mg}$ loading dose. ${ }^{21}$ This study also found no changes in IPA or after a loading dose during atorvastatin coadministration. Atorvastatin maintenance dose of $80 \mathrm{mg}$ per day increased the $\mathrm{AUC}_{0-\mathrm{t}}$ for prasugrel's active metabolite by $17 \%$ but did not cause an increase in IPA. An open-label, randomized, 2-period, 2-parallel group study found that coadministration with ketaconzole decreased the active metabolite concentration of prasugrel by approximately 50\%; however, the extent of exposure to the active metabolite and the elimination half-life did not change and was not associated with a reduced IPA. ${ }^{22}$

\section{Efficacy}

The Trial to Assess Improvement in Therapeutic Outcomes by Optimizing Platelet Inhibition with Prasugrel-Thrombolysis in Myocardial Infarction (TRITON-TIMI) 38 compared prasugrel with clopidogrel in patients with ACS and scheduled PCI. ${ }^{23}$ Data from TRITON-TIMI 38 were available as a published manuscript and as an FDA review. Inclusion criteria for patients with UA or NSTEMI were ischemic symptoms lasting 10 minutes or more and occurring within 72 hours before randomization, a TIMI risk score of 3 or more, and either ST segment deviation of $1 \mathrm{~mm}$ or more or elevated levels of a cardiac biomarker of necrosis. Patients with STEMI could be enrolled within 12 hours after onset of symptoms if PCI was planned within 14 days. Exclusion criteria included increased risk of bleeding, anemia, thrombocytopenia, history of pathologic intracranial findings, or use of a thienopyridine within 5 days before enrollment. ${ }^{23}$

A total of 13,608 patients were enrolled including 10,074 with moderate- to high-risk unstable angina or non-ST-elevation myocardial infarction (NSTEMI/UA) and 3,534 with ST-elevation myocardial infarction (STEMI). ${ }^{23}$ Patients were randomized to prasugrel $60 \mathrm{mg}$ as a loading dose and $10 \mathrm{mg}$ once daily maintenance or clopidogrel $300 \mathrm{mg}$ loading dose and $75 \mathrm{mg}$ once 
Critical Review of Prasugrel for Formulary Decision Makers

TABLE 2 Efficacy End Points at 15 Months of TRITON-TIMI 38 and Subanalysis of STEMI Patients

\begin{tabular}{|c|c|c|c|c|c|c|}
\hline Patients & Treatment & End Point & $\begin{array}{l}\text { Prasugrel + aspirin } \\
\quad(n=6,813)\end{array}$ & $\begin{array}{l}\text { Clopidogrel + aspirin } \\
\qquad(\mathbf{n}=6,795)\end{array}$ & HR $(95 \%$ CI $)$ & $P$ Value \\
\hline \multirow[t]{5}{*}{$\begin{array}{l}\text { Patients with ACS } \\
\text { scheduled for PCIa }\end{array}$} & \multirow{5}{*}{$\begin{array}{c}\text { Prasugrel } 60 \mathrm{mg} \text { then } \\
10 \mathrm{mg} \text { daily } \\
\text { or } \\
\text { Clopidogrel } 300 \mathrm{mg} \text { then } \\
75 \mathrm{mg} \text { daily } \\
\text { All patients received aspirin } \\
75 \text { mg-162 mg daily }\end{array}$} & $\begin{array}{l}\text { CV death, nonfatal } \\
\text { MI, nonfatal stroke } \\
\text { (Primary) }\end{array}$ & $9.9 \%(643)$ & $12.1 \%(781)$ & $0.81 \quad(0.73-0.90)$ & $<0.001$ \\
\hline & & All cause mortality & $3.0 \%(188)$ & $3.2 \%(197)$ & $0.95(0.78-1.16)$ & 0.64 \\
\hline & & CV death & $2.1 \%(133)$ & $2.4 \%(150)$ & $0.89(0.70-1.12)$ & 0.31 \\
\hline & & Nonfatal MI & $7.3 \%(475)$ & $9.5 \%(620)$ & $0.76 \quad(0.67-0.85)$ & $<0.001$ \\
\hline & & Nonfatal stroke & $1.0 \% \quad(61)$ & $1.0 \% \quad(60)$ & $1.02(0.71-1.45)$ & 0.93 \\
\hline Patients & Treatment & End Point & $\begin{array}{l}\text { Prasugrel + aspirin } \\
\quad(\mathrm{n}=1,769)\end{array}$ & $\begin{array}{l}\text { Clopidogrel + aspirin } \\
\quad(\mathrm{n}=1,765)\end{array}$ & HR (95\% CI) & $P$ Value \\
\hline \multirow{5}{*}{$\begin{array}{l}\text { Sub-analysis of } \\
\text { patients with } \\
\text { STEMI scheduled } \\
\text { for PCI }\end{array}$} & \multirow{5}{*}{$\begin{array}{c}\text { Prasugrel } 60 \mathrm{mg} \text { then } \\
10 \mathrm{mg} \text { daily } \\
\text { or } \\
\text { Clopidogrel } 300 \mathrm{mg} \text { then } \\
75 \mathrm{mg} \text { daily } \\
\text { All patients received aspirin } \\
75 \mathrm{mg}-162 \mathrm{mg} \text { daily }\end{array}$} & $\begin{array}{l}\text { CV death, nonfatal } \\
\text { MI, nonfatal stroke } \\
\text { (Primary) }\end{array}$ & $10.0 \%(174)$ & $12.4 \%(216)$ & $0.79(0.65-0.97)$ & 0.022 \\
\hline & & All cause mortality & $(58)$ & $(76)$ & $0.76(0.54-1.07)$ & 0.113 \\
\hline & & CV death & (43) & (58) & $0.74(0.50-1.09)$ & 0.129 \\
\hline & & Nonfatal MI & (119) & $(157)$ & $0.75(0.59-0.95)$ & 0.016 \\
\hline & & Nonfatal stroke & (26) & (25) & $1.03(0.60-1.79)$ & 0.911 \\
\hline
\end{tabular}

aU.S. Food and Drug Administration. February 3, 2009;10 Wiviott, SD et al. N Engl J Med. 2007:357(20):2001-15.23

${ }^{b}$ Montalescot $G$, et al. Lancet. 2009;373(9665):723-31.26

ACS = acute coronary syndromes; $C V=$ cardiovascular; HR=hazard ratio; $M I=$ myocardial infarction; $P C I=$ percutaneous coronary intervention; STEMI=ST-elevation myocardial infarction; TRITON-TIMI = Trial to Assess Improvement in Therapeutic Outcomes by Optimizing Platelet Inhibition with Prasugrel-Thrombolysis in Myocardial Infarction.

daily maintenance. ${ }^{23}$ The loading dose was administered between randomization and 1 hour after leaving the cardiac catheterization laboratory. ${ }^{23}$ The loading dose was administered before PCI in $25 \%$ of patients and during or within 1 hour after PCI in $74 \%$ of patients. ${ }^{23}$ All patients received aspirin $75-162 \mathrm{mg}$ daily. ${ }^{23}$ Adjunctive medication for PCI was at the discretion of the treating physician and included heparin, low molecular weight heparin, bivalirudin, and glycoprotein IIb/IIIa inhibitors. ${ }^{23}$ Baseline characteristics and demographics of patients were well matched between groups. ${ }^{23}$ Follow-up was between 6 and 15 months, with a median duration of therapy of 14.5 months. ${ }^{23}$

The primary efficacy end point was the composite of death from cardiovascular causes, nonfatal MI, or nonfatal stroke. ${ }^{23}$ The key secondary end point was the composite of death from cardiovascular causes, nonfatal MI, and need for urgent target revascularization..$^{23}$ The primary end point was similar to those studied for clopidogrel. The CURE study compared clopidogrel plus aspirin with aspirin alone for the composite end point of cardiovascular death, nonfatal MI, and stroke in patients with UA/NSTEMI. ${ }^{24}$ The PCI-CLARITY study analyzed the same end point between PCI and 30 days post for clopidogrel in patients with STEMI. ${ }^{25}$

The primary end point occurred in 643 patients (9.9\%) in the prasugrel group and 781 patients $(12.1 \%)$ in the clopidogrel group (HR=0.81, 95\% CI=0.73-0.90, $P<0.001){ }^{23}$ The number needed to treat (NNT) with prasugrel versus clopidogrel to avoid 1 primary end point was 46 . Superiority of prasugrel was evident as early as 3 days with $4.7 \%$ of patients having the primary end point compared with $5.6 \%$ in the clopidogrel group (HR $=0.82$, $95 \% \mathrm{CI}=0.71-0.96, P=0.01) .{ }^{23}$ This difference persisted to the end of the study (5.6\% prasugrel group vs. $6.9 \%$ clopdiogrel group; $\mathrm{HR}=0.8,95 \% \mathrm{CI}=0.7-0.93, P=0.003) .{ }^{23}$ Prasugrel achieved significantly improved outcomes compared with clopidogrel for several secondary end points (Table 2).

A subanalysis of TRITION-TIMI 38 involving the STEMI trial population was performed by Montalescot et al. (2009). ${ }^{26}$ The analysis included 3,534 patients stratified by those receiving PCI within 12 hours of symptom onset (primary PCI) and those receiving PCI 12 hours to 14 days after symptom onset (secondary PCI). The primary end point at 15 months occurred in 174 patients $(10.0 \%)$ in the prasugrel group compared with 216 patients $(12.4 \%)$ in the clopidogrel group ( $\mathrm{HR}=0.79,95 \%$ $\mathrm{CI}=0.65-0.97, P=0.022$; Table 2) ${ }^{26}$ Prasugrel was significantly better than clopidogrel for the primary end point in patients with secondary PCI $(P=0.015)$ but not primary PCI $(P=0.266){ }^{26}$ At 15 months, there was no difference between prasugrel and clopidogrel in cardiovascular death $(2.4 \%$ vs. $3.4 \%, P=0.129)$ or all-cause death $(3.3 \%$ vs. $4.3 \%, P=0.113){ }^{26}$ The authors of the TRITON-TIMI 38 trial emphasized that the study was not prospectively designed or powered to show superiority of prasugrel over clopidogrel in the STEMI cohort alone. ${ }^{26}$

The TRITON-TIMI 38 results were driven by the difference in nonfatal MI between prasugrel (475 events, $7.3 \%$ ) and clopidogrel $(620 \text { events, 9.5\%) }(P<0.001))^{10,23}$ The NNT was 48 . 
Critical Review of Prasugrel for Formulary Decision Makers

TABLE 3 Incidence of Bleeding Events in TRITON-TIMI 38

\begin{tabular}{|c|c|c|c|c|}
\hline \multicolumn{5}{|c|}{ Non-CABG-Related Bleeding } \\
\hline Bleeding End Point & Prasugrel $(n=6,741)$ & Clopidogrel $(n=6,716)$ & $\operatorname{HR}(95 \% \mathrm{CI})$ & $P$ Value \\
\hline TIMI fatal & $0.3 \% \quad(21)$ & $0.1 \% \quad(5)$ & $4.19 \quad(1.58-11.1)$ & 0.002 \\
\hline TIMI life threateninga & $1.3 \%(\mathrm{n}=85)$ & $0.8 \% \quad(56)$ & $1.52(1.08-2.13)$ & 0.015 \\
\hline TIMI majorb & $2.2 \% \quad(146)$ & $1.7 \%(111)$ & $1.32(1.03-1.68)$ & 0.029 \\
\hline TIMI minorc & (164) & $1.9 \%(125)$ & $1.31 \quad(1.04-1.66)$ & 0.022 \\
\hline TIMI minimald & $(460)$ & $4.7 \%(314)$ & $1.47 \quad(1.28-1.70)$ & 0.022 \\
\hline \multicolumn{5}{|c|}{ CABG-Related Bleeding } \\
\hline Bleeding End Point & Prasugrel $(n=213)$ & Clopidogrel $(n=224)$ & HR $(95 \% \mathrm{CI})$ & $P$ Value \\
\hline TIMI fatal & $0.9 \% \quad(2)$ & $0 \%$ & & \\
\hline TIMI life threateninga & $11.3 \% \quad(24)$ & $3.6 \% \quad(8)$ & $3.50 \quad(1.53-7.99)$ & 0.002 \\
\hline \multicolumn{5}{|c|}{$\begin{array}{l}\text { Source: U.S. Food and Drug Administration. February 3, } 2009.10 \\
\text { aTIMI life-threatening bleeding = a subset of TIMI major bleeding in which "life-threatening" is fatal, or causes hypotension that requires intravenous inotropic agents, or } \\
\text { surgical intervention, or } 4 \text { or more units of blood or packed red blood cells within } 48 \text { hours, or symptomatic ICH. } \\
\text { bTIMI major bleeding = any ICH or overt bleeding associated with an } \mathrm{Hb} \text { decrease from baseline of } 5 \mathrm{gm} \text { or more per dL. } \\
\text { 'TIMI minor bleeding = clinically overt bleeding associated with an } \mathrm{Hb} \text { decrease from baseline equal to or greater than } 3 \mathrm{gm} \text { per dL but less than } 5 \mathrm{gm} \text { per dL. } \\
\text { dTIMI minimal bleeding = an Hb decrease from baseline less than } 3 \mathrm{gm} \text { per dL. } \\
\text { CABG = coronary artery bypass graft; Hb=hemoglobin; HR=hazard ratio; ICH=intracranial hemorrhage; TIMI= thrombolysis in myocardial infarction; TRITON= Trial } \\
\text { to Assess Improvement in Therapeutic Outcomes by Optimizing Platelet Inhibition with Prasugrel. }\end{array}$} \\
\hline
\end{tabular}

Cardiovascular death and nonfatal stroke outcomes were not significantly different between the prasugrel and clopidogrel groups (Table 2). ${ }^{10,23}$ These data led the FDA reviewer to recommend that prasugrel's indication be limited to prevention of MI post PCI. ${ }^{10}$

\section{Safety}

Safety end points in the TRITON-TIMI 38 trial included TIMI major bleeding not related to coronary artery bypass grafting (CABG), non-CABG related TIMI life-threatening bleeding, and TIMI major and minor bleeding. Non-CABG TIMI major hemorrhage occurred in 146 patients (2.4\%) in the prasugrel group compared with 111 patients (1.8\%) in the clopidogrel group (HR $=1.32,95 \% \mathrm{CI}=1.03-1.68, P=0.03) .{ }^{23}$ Prasugrel was associated with a significantly higher rate of life-threatening bleeds ( 85 patients, 1.4\%) compared with clopidogrel (56 patients, 0.9\%) (HR=1.52, 95\% CI=1.08-2.13, $P=0.01){ }^{23}$ Fatal TIMI major hemorrhage occurred in 21 patients $(0.4 \%)$ in the prasugrel group compared with 5 patients $(0.1 \%)$ in the clopidogrel group (HR=4.19, 95\% CI =1.58-11.11, $P=0.002) .{ }^{23}$ All 5 fatal bleeds in the clopidogrel group were intracranial hemorrhage. Fatal bleeding sites in the prasugrel group included intracranial hemorrhage (9 patients), gastrointestinal (5 patients), puncture and surgical sites (2 patients each), retroperitoneal locations (2 patients), and intra-abdominal location (1 patient). ${ }^{10}$

CABG-related TIMI major bleeding occurred in 24 patients (13.4\%) in the prasugrel group compared with 6 patients (3.2\%) in the clopidogrel group (HR=4.73, 95\% CI=1.9-11.82, $P<0.001) .{ }^{23}$ Fatal CABG-related bleeding occurred in 2 patients

\section{TABLE 4 Incidence of Bleeding Events in TRITON-TIMI 38 Subanalysis of STEMI Patients}

\begin{tabular}{|c|c|c|c|c|}
\hline \multicolumn{5}{|c|}{ Non-CABG-Related Bleeding } \\
\hline Bleeding End Point & $\begin{array}{l}\text { Prasugrel } \\
(\mathrm{n}=1,769)\end{array}$ & $\begin{array}{c}\text { Clopidogrel } \\
(\mathrm{n}=1,765)\end{array}$ & HR $(95 \% \mathrm{CI})$ & $\begin{array}{c}P \\
\text { Value }\end{array}$ \\
\hline TIMI fatal & $0.45 \%(7)$ & $0.13 \%(2)$ & $3.48(0.72-16.75)$ & 0.097 \\
\hline TIMI life threateninga & $1.3 \%(20)$ & $1.1 \%(18)$ & $1.11(0.59-2.10)$ & 0.750 \\
\hline TIMI majorb & $2.4 \%(38)$ & $2.1 \%(34)$ & $1.11 \quad(0.70-1.77)$ & 0.645 \\
\hline \multicolumn{5}{|c|}{ CABG-Related Bleeding } \\
\hline Bleeding End Point & $\begin{array}{c}\text { Prasugrel } \\
(\mathrm{n}=213)\end{array}$ & $\begin{array}{c}\text { Clopidogrel } \\
(\mathrm{n}=224)\end{array}$ & HR (95\% CI) & $\begin{array}{c}P \\
\text { Value }\end{array}$ \\
\hline TIMI majorb & $18.8 \%(12)$ & $2.7 \% \quad(2)$ & $8.19(1.76-38.18)$ & 0.003 \\
\hline TIMI major or minor $\mathrm{b}, \mathrm{c}$ & $21.9 \%(14)$ & $4.1 \% \quad(3)$ & $6.53(1.78-23.94)$ & 0.003 \\
\hline
\end{tabular}

Source: Montalescot G, et al. Lancet. 2009;373(9665);723-31.26

aTIMI life-threatening bleeding = a subset of TIMI major bleeding in which "lifethreatening" is fatal or causes hypotension that requires intravenous inotropic agents or surgical intervention, or 4 or more units of blood or packed red blood cells within 48 hours or symptomatic ICH.

${ }^{b}$ TIMI major bleeding = any ICH or overt bleeding associated with an $\mathrm{Hb}$ decrease from baseline of $5 \mathrm{gm}$ or more per $\mathrm{dL}$.

'TIMI minor bleeding = clinically overt bleeding associated with an $\mathrm{Hb}$ decrease from baseline equal to or greater than $3 \mathrm{gm}$ per $d \mathrm{~L}$ but less than $5 \mathrm{gm}$ per $\mathrm{dL}$. $C A B G=$ coronary artery bypass graft; $H b=$ hemoglobin; $H R=$ hazard ratio; $I C H=$ intracranial hemorrhage; STEMI = ST-elevation myocardial infarction; TIMI = thrombolysis in myocardial infarction; TRITON = Trial to Assess Improvement in Therapeutic Outcomes by Optimizing Platelet Inhibition with Prasugrel.

in the prasugrel group and none (0) in the clopidogrel group..$^{10} \mathrm{An}$ FDA review concluded that CABG-related TIMI major bleeding associated with prasugrel was a cause for concern in the setting of urgent CABG. On February 3, 2009, the FDA Cardiovascular and 
Renal Drugs Advisory Committee recommended that prasugrel be avoided around CABG or surgical procedures. ${ }^{10}$ The committee also recommended that preference to prasgurel be given only when coronary anatomy was known. Bleeding results from TRITON-TIMI 38 can be found in Tables 3 and 4 .

According to the FDA review, prasugrel may not be appropriate for patients with a prior history of transient ischemic attack (TIA) or stroke. A subanalysis of the TRITON-TIMI 38 trial data revealed a net harm for this patient group when treated with prasugrel $(\mathrm{HR}=1.54,95 \% \mathrm{CI}=1.02-2.32, P=0.04) .{ }^{23} \mathrm{~A}$ total of 518 patients with prior history of TIA or stroke were enrolled in TRITON-TIMI 38 and randomized to prasugrel $(n=262)$ or clopidogrel $(n=256) .{ }^{10}$ In contrast to the overall study results that found prasugrel superior to clopidogrel for the primary end point, 47 patients (17.9\%) with history of stroke or TIA in the prasugrel group and 35 patients (13.7\%) in the clopidogrel group experienced a primary end point event $(\mathrm{HR}=1.38,95 \% \mathrm{CI}=0.89-2.13$, $P=0.15) .{ }^{10}$ Stroke occurred in $17(6.5 \%)$ and 3 patients (1.2\%) in this cohort treated with prasugrel and clopidogrel, respectively (HR $=5.64,95 \% \mathrm{CI}=1.65-19.3, P=0.002) .{ }^{10}$ In patients without a prior history of stroke or TIA, a stroke occurred in $58(0.9 \%)$ and 68 subjects $(1.0 \%)$ treated with prasugrel and clopidogrel, respectively ( $\mathrm{HR}=0.85,95 \% \mathrm{CI}=0.6-1.21, P=0.36) .{ }^{10}$ Additionally, patients with a recent history of hemorrhagic stroke or ischemic stroke (up to 3 months prior to screening) were excluded from TRITON-TIMI 38. ${ }^{10}$ The safety concerns regarding use of prasugrel in this patient group led the Cardiovascular and Renal Drugs Advisory Committee to recommend that prasugrel be contraindicated in patients with prior history of stroke or TIA. ${ }^{27}$

Two other patient subgroups were identified for additional analysis in TRITON-TIMI 38: patients weighing $\leq 60 \mathrm{~kg}$ or 75 years of age and older. Patients with body weight of $60 \mathrm{~kg}$ or less experienced no net clinical benefit with prasugrel compared with clopidogrel $(\mathrm{HR}=1.03,95 \% \mathrm{CI}=0.69-1.53, P=0.89) .{ }^{23}$ The FDA review stated that while the relative risk for bleeding with prasugrel was higher in this subgroup $(\mathrm{HR}=1.72,95 \% \mathrm{CI}=1.07-2.79$, $P<0.05)$, the body weight cutoff was arbitrary and the subgroup was small $(n=856) \cdot{ }^{10}$ Patients 75 years of age and older $(n=1,809)$ had no net benefit from prasugrel ( $\mathrm{HR}=0.99,95 \% \mathrm{CI}=0.81-1.21$, $P=0.92) .{ }^{23}$ Non-CABG TIMI major or minor bleeding occurred in $80(9.0 \%)$ and 62 patients (6.9\%) 75 years of age and older in the prasugrel and clopidogrel groups, respectively ( $\mathrm{HR}=1.35$, $95 \% \mathrm{CI}=0.97-1.88, \mathrm{P}=0.078) .{ }^{10}$ Of these patients, $9(1.0 \%)$ in the prasugrel group and $1(0.1 \%)$ in the clopidogrel group died of hemorrhage. ${ }^{10}$

\section{Managed Care Considerations}

Selected efficacy and safety end points including death from any cause, nonfatal MI, nonfatal stroke, and TIMI major bleed were used in an analysis to determine net clinical benefit. ${ }^{23}$ The analysis favored patients in the prasugrel group (12.2\%) compared with those treated with clopidogrel (13.9\%) $(\mathrm{HR}=0.87,95 \%$
$\mathrm{CI}=0.79-0.95, P=0.004) .{ }^{23}$ Death from cardiovascular causes or fatal hemorrhage occurred in 142 (2.2\%) and 151 patients (2.4\%) in the prasugrel and clopidogrel groups, respectively ( $H R=0.94$, 95\% CI $=0.75-1.18, P=0.59) .{ }^{23}$ Wiviott et al. stated that the number needed to treat with prasugrel compared with clopidogrel to avoid 1 primary efficacy end point was $46 .{ }^{23}$ The number needed to harm for 1 excess non-CABG related TIMI major hemorrhage was 167, and 10 for 1 excess CABG-related TIMI major hemorrhage. ${ }^{23}$

The FDA review displayed the risk-benefit profile in quantitative terms. ${ }^{10}$ For each 1,000 patients treated with prasugrel instead of clopidogrel, there were the following:

24 cardiovascular end points prevented:

- 21 nonfatal myocardial infarctions

- 3 cardiovascular deaths

- 0 strokes

10 excess TIMI major or minor bleeding events would occur, comprising the following:

- 2 fatal bleeding events

- 3 nonfatal TIMI major bleeding events (intracranial hemorrhage or a hemoglobin $(\mathrm{Hb})$ decrease greater than 5 gm per dL)

- 5 TIMI minor bleeds (Hb decrease between 3 gm and 5 gm per dL)

The FDA review division stated that this was a worthwhile risk-benefit profile..$^{10}$ On February 3, 2009, the Cardiovascular and Renal Drugs Advisory Committee voted unanimously (9-0) for approval of prasugrel to treat patients with ACS. ${ }^{27}$

Hospital and managed care formulary decision makers may view prasugrel differently based on the efficacy and safety in relation to time. The FDA conducted an analysis of the TRITONTIMI 38 data to determine how prasugrel affects clinical end points over time. A plot of the treatment difference between prasugrel and clopidogrel was generated for the STEMI and NSTEMI/ UA patient groups over 450 days (Figure 1). The data showed that for patients with STEMI, the maximum benefit was achieved at 18 days and remained constant thereafter. ${ }^{10}$ In contrast, the benefit for patients experiencing NSTEMI/UA continued to grow throughout the study. ${ }^{10}$

An analysis of end points prevented per bleeding event was also conducted. The FDA review stated that the benefit between efficacy and bleeding was greatest at day 12 and gradually declined to day $80 .{ }^{10}$ Between days 80 and 180 , the relationship was constant. ${ }^{10}$ These data show that the risk-benefit appears to be greatest early in therapy with prasugrel, with fewer end points prevented per bleed as therapy is continued (Figure 2). Managed care decision makers should consider careful patient selection and duration of use to maximize the benefit-risk profile of prasugrel. 


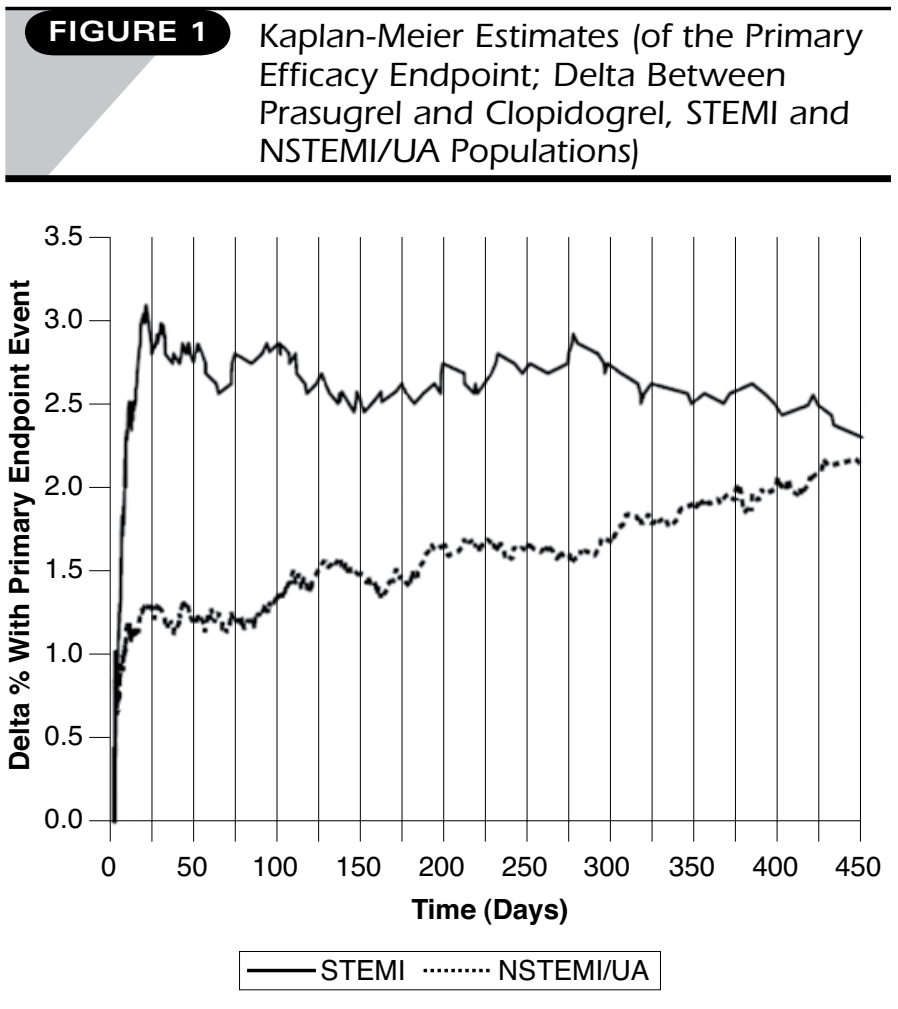

Adapted from U.S. Food and Drug Administration. February 3, 2009. Figure 7, p. 35.10

NSTEMI =non-ST-elevation myocardial infarction; STEMI=ST-elevation myocardial infarction; $U A=$ unstable angina.

\section{Conclusions}

Prasugrel demonstrated superiority for multiple cardiovascular end points compared with standard-dose clopidogrel in a randomized, double blind superiority trial but was also associated with an increased bleeding risk, including fatal bleeds. Patients with a prior history of stroke or TIA are at risk of bleeding with prasugrel, and a contraindication in this population has been recommended. ${ }^{20}$ ACS continues to be 1 of the leading causes of morbidity and mortality in the United States; its prevalence underscores the need to provide safe, effective therapies.

The formulary decision maker has several issues to consider regarding addition of prasugrel. Patents on clopidogrel are anticipated to expire in 2011 and be followed by the release of low cost generics. However, history has shown that generic launches may be delayed when multiple patents are present. Prasugrel has only 1 phase III clinical outcomes trial and will likely not be addressed immediately in cardiovascular guidelines. Questions remain regarding optimal dosing and proper patient selection. Clopidogrel is indicated for patients with recent MI, stroke, or established peripheral artery disease and for patients with ACS who are medically managed or following PCI/CABG. ${ }^{13}$ Additionally, clopdiogrel is recommended in combination with
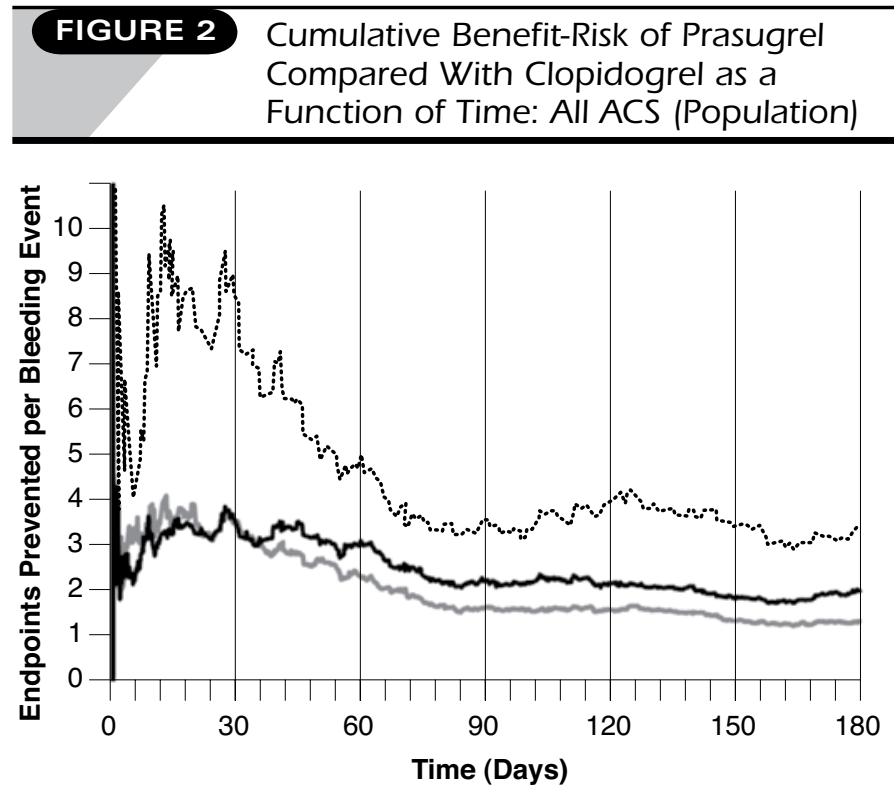

\[ \text { SAE Bleeds …...... TMI Major - TMI Major or Minor } \]
Adapted from U.S. Food and Drug Administration. February 3, 2009. Figure 16,
p. 55.10
aTIMI major bleeding = any ICH or overt bleeding associated with an Hb decrease
from baseline of $5 \mathrm{gm}$ or more per $\mathrm{dL}$.
bTIMI minor bleeding = clinically overt bleeding associated with an $\mathrm{Hb}$ decrease
from baseline equal to or greater than 3 gm per $\mathrm{dL}$ but less than $5 \mathrm{gm}$ per $\mathrm{dL}$.
ACS = acute coronary syndrome; Hb=hemoglobin; $\mathrm{ICH}=$ intracranial hemorrhage;
SAE= serious adverse event; TIMI = thrombolysis in myocardial infarction.

aspirin for secondary prevention of cardiovascular events following ACS. ${ }^{3-6}$ The added bleeding risks and negative findings in patients with prior history of stroke indicate that prasugrel cannot completely replace clopidogrel.

Prasugrel requires a risk-benefit approach when considering placement on the formulary. The benefit of cardiovascular end points prevented compared with bleeding events was largest in the first weeks. ${ }^{10}$ Hospital formulary decision makers should consider the benefit since patients will be initiated on therapy in this setting. Data on the use of prasugrel in ACS patients outside the inclusion criteria of TRITON-TIMI 38 are scarce. A phase III clinical trial (TRILOGY ACS, NCT00699998) is currently underway in which prasugrel plus aspirin is compared with clopidogrel plus aspirin in patients with UA/NSTEMI who are medically managed (do not undergo acute coronary revascularization) with estimated completion in 2011-2012. ${ }^{28}$ An analysis of clopidogrel prescriptions found that only $47 \%$ of patients met "literature based" criteria, and 39\% met the FDA-approved indication;29 a similar challenge is likely to occur with prasugrel in which the drug could be hazardous in select patient populations (e.g., CABG, prior TIA/stroke).

Until more data are available in other patient groups, 
managed care decision makers may consider implementing strategies ensuring that prasugrel is used in the patient population represented in TRITON-TIMI 38, with judicious monitoring of member safety. Patients likely to benefit include those younger than 75 with no history of stroke, undergoing PCI (not CABG). Hospital decision makers may consider developing order sets supporting proper patient selection for initiation of therapy.

\section{Authors}

JEREMY A. SCHAFER, PharmD, is Manager of Formulary Development; NICOLE K. KJESBO, PharmD, BCPS, is Senior Clinical Pharmacist; and PATRICK P. GLEASON, PharmD, BCPS, FCCP, is Director of Outcomes Assessment, Prime Therapeutics LLC., Eagan, Minnesota. Patrick Gleason is also Associate Professor, College of Pharmacy, University of Minnesota, Minneapolis, Minnesota.

AUTHOR CORRESPONDENCE: Jeremy A. Schafer, PharmD, Prime Therapeutics, 1305 Corporate Center Drive, Eagan, MN 55121. Tel.: 612.777.5097; Fax: 612.777.5143;

E-mail: jschafer@primetherapeutics.com

\section{DISCLOSURES}

The authors report no financial or other conflicts of interest related to the subject of this article. Prime Therapeutics, LLC, is a pharmacy benefits management company for stand-alone pharmacy plans and for health plans.

Schafer and Kjesbo conducted the literature search with assistance from Gleason. Concept, design, and data interpretation were the work of all 3 authors. Schafer was the primary writer of the manuscript with assistance from Kjesbo. The revision of the manuscript was the work of all 3 authors.

\section{REFERENCES}

1. Lloyd-Jones D, Adams R, Carnethon M, et al. Heart disease and stroke statistics—2009 update: a report from the American Heart Association Statistics Committee and Stroke Statistics Subcommittee. Circulation. 2009;119(3):480-86. Available at: http://circ.ahajournals.org/cgi/ reprint/119/3/480. Accessed April 24, 2009.

2. King SB 3rd, Smith SC Jr, Hirshfeld JW Jr, et al. 2007 focused update of the ACC/AHA/SCAI 2005 guideline update for percutaneous coronary intervention: a report of the American College of Cardiology/American Heart Association Task Force on Practice Guidelines. Circulation. 2008;117(2):26195. Available at: http://circ.ahajournals.org/cgi/reprint/117/2/261. Accessed April 24, 2009.

3. Antman EM, Hand M, Armstrong PW, et al. 2007 focused update of the ACC/AHA 2004 guidelines for the management of patients with ST-elevation myocardial infarction: a report of the American College of Cardiology/American Heart Association Task Force on Practice Guidelines. Circulation. 2008;117(2):296-330. Available at: http://circ.ahajournals.org/cgi/ reprint/117/2/296. Accessed April 21, 2009.

4. Anderson JL, Adams CD, Antman EM, et al. ACC/AHA 2007 guidelines for the management of patients with unstable angina/non-ST-elevation myocardial infarction: a report of the American College of Cardiology/ American Heart Association Task Force on Practice Guidelines (Writing committee to revise the 2002 guidelines for the management of patients with unstable angina/non-ST-elevation myocardial infarction). J Am Coll Cardiol. 2007;50(7):el-e157. Available at: http://content.onlinejacc.org/cgi/ reprint/50/7/el.pdf. Accessed April 21, 2009.

5. Goodman SG, Menon V, Cannon CP, et al. Acute ST-segment elevation myocardial infarction. American College of Chest Physicians Evidence-Based Clinical Practice Guidelines (8th edition). Chest. 2008;133(6 Suppl):708S775 S.

6. Harrington RA, Becker RC, Cannon CP, et al. Antithrombotic therapy for non-ST-segment elevation acute coronary syndromes: American College of Chest Physicians Evidence-Based Clinical Practice Guidelines (8th edition) Chest. 2008;133(6 Suppl):670S-707S.

7. National Center for Health Statistics. HIST290A: deaths for selected causes by 10-year age groups, race, and sex: death registration states, 190032, and United States, 1933-98. Available at: http://www.cdc.gov/nchs/ datawh/statab/unpubd/mortabs/hist290a.htm. Accessed April 24, 2009.

8. National Center for Health Statistics. GMWK292F: deaths for 358 selected causes by 5-year age groups, race, and sex: United States, 1999 -2004. Available at: http://www.cdc.gov/nchs/datawh/statab/unpubd/mortabs/ gmwk292_10.htm. Accessed April 24, 2009.

9. DeFrances CJ, Lucas CA, Buie VC, Golosinskiy A. 2006 National Hospital Discharge Survey. Natl Health Stat Rep. 2008;5:1-20.

10. U.S. Food and Drug Administration. Cardiovascular and Renal Drug Advisory Committee briefing document on prasugrel for ACS. February 3, 2009. Available at: http://www.fda.gov/ohrms/dockets/ac/09/briefing/20094412bl-01-FDA.pdf. Accessed April 24, 2009.

11. Bhatt DL, Roe MT, Peterson ED. Utilization of early invasive management strategies for high-risk patients with non-ST-segment elevation acute coronary syndromes. JAMA. 2004;292(17):2096-104.

12. Farid NA, Smith RL, Gillespie TA, et al. The disposition of prasugrel, a novel thienopyridine, in humans. Drug Metab Dispos. 2007;35(7):1096-104.

13. U.S. Food and Drug Administration. Plavix (clopidogrel). NDA no. 020839/S-038. Approved November 17, 1997. Available at: http://www.fda.gov/ cder/foi/label/2007/020839s038lbl.pdf. Accessed April 14, 2009.

14. Riley AB, Tafreshi MJ, Haber SL. Prasugrel: a novel antiplatelet agent. Am J Health Syst Pharm. 2008;65(11):1019-28.

15. Niitsu Y, Jakubowski JA, Sugidachi A, Asai F. Pharmacology of CS-747 (prasugrel, LY640315), a novel, potent antiplatelet agent with in vivo P2Y 12 receptor antagonist activity. Semin Thromb Hemost. 2005;31(2):184-94.

16. Rehmel JL, Eckstein JA, Farid NA, et al. Interactions of two major metabolites of prasugrel, a thienopyridine antiplatelet agent, with the cytochromes P450. Drug Metab Dispos. 2006;34(4):600-07.

17. Wiviott SD, Trenk D, Frelinger AL, et al. Prasugrel compared with high loading- and maintenance-dose clopidogrel in patients with planned percutaneous coronary intervention: the Prasugrel in Comparison to Clopdiogrel for Inhibition of Platelet Activation and Aggregation Thrombolysis in Myocardial Infarction 44 trial. Circulation. 2007;116(25):2923-32. Available at: http://circ.ahajournals.org/cgi/reprint/116/25/2923. Accessed April 24, 2009.

18. Ho PM, Maddox TM, Wang L, et al. Risk of adverse outcomes associated with concomitant use of clopidogrel and proton pump inhibitors following acute coronary syndrome. JAMA. 2009;301(9):937-44.

19. Small DS, Farid NA, Payne CD, et al. Effects of the proton pump inhibitor lansoprazole on the pharmacokinetics and pharmacodynamics of prasugrel and clopidogrel. J Clin Pharmacol. 2008;48(4):475-84.

20. Small DS, Farid NA, Li YG, et al. Effect of ranitidine on the pharmacokinetics and pharmacodynamics of prasugrel and clopidogrel. Curr Med Res Opin. 2008;24(8):2251-57. 
21. Farid NA, Small DS, Payne CD, et al. Effect of atorvastatin on the pharmacokinetics and pharmacodynamics of prasugrel and clopidogrel in healthy subjects. Pharmacotherapy. 2008;28(12):1483-94.

22. Farid NA, Payne CD, Small DS, et al. Cytochrome P450 3A inhibition by ketoconazole affects prasugrel and clopidogrel pharmacokinetics and pharmacodynamics differently. Clin Pharmacol Ther. 2007;81(5):735-41.

23. Wiviott SD, Braunwald E, McCabe $\mathrm{CH}$, et al. Prasugrel versus clopidogrel in patients with acute coronary syndromes. N Engl J Med. 2007;357(20):2001-15. Available at: http://content.nejm.org/cgi/ reprint/357/20/2001.pdf. Accessed April 24, 2009.

24. Yusuf S, Zhao F, Mehta SR, et al. Effects of clopidogrel in addition to aspirin in patients with acute coronary syndromes without ST-segment elevation. N Engl J Med. 2001;345(7):494-502. Available at: http://content.nejm. org/cgi/reprint/345/7/494.pdf. Accessed April 21, 2009.

25. Sabatine MS, et al. Effect of clopidogrel pretreatment before percutaneous coronary intervention in patients with ST-elevation myocardial infarction treated with fibrinolytics: the PCI-CLARITY study. JAMA 2005;294(10):1224-32.
26. Montalescot G, Wiviott SD, Braunwald E, et al. Prasugrel compared with clopidogrel in patients undergoing percutaneous coronary intervention for ST-elevation myocardial infarction (TRITON-TIMI 38): double-blind, randomized controlled trial. Lancet. 2009;373(9665):723-31.

27. U.S. Food and Drug Administration. Summary minutes of the Cardiovascular and Renal Drugs Advisory Committee February 3, 2009. Available at: http://www.fda.gov/ohrms/dockets/ac/09/minutes/20094412ml-Final.pdf. Accessed April 24, 2009.

28. U.S. National Institutes of Health. Clinical trial search for prasugrel. Available at: http://www.clinicaltrials.gov/ct2/results?term=prasugrel. Accessed April 21, 2009

29. Jackson MA, Fairman KA, Curtiss FR. Prior authorization and clopiodgrel use: the truth lies in the details. J Manag Care Pharm. 2009;15(1):7177. Available at: http://www.amcp.org/data/jmcp/071-077.pdf. 